\title{
Substantiation of Process Variables and Modes of Heavy Spring-Tooth Harrow
}

\author{
Alexey Genrichovitsch Ivanov, Alexander Vladimirovich Kostin, Renat Ravilevich Shakirov, Fanis \\ Raschidovitch Arslanov, Yurii Genadevitch Korepanov \\ Izhevsk State Agricultural Academy, Russia
}

\begin{abstract}
Nowadays soil cultivation applies harrowing. It is commonly carried out using heavy harrows with spring-tooth tools which can break soil crust, they are applied for spring mulching, distribution of stubbles, covering of seeds and fertilizers, they can act as tillers. However, there is no single opinion concerning the influence of variables of spring-tooth tool and harrow speed on quality of its operation, thus defining the aim of this work. Operation of spring-tooth tool of heavy chisel harrow has been experimentally studied, optimum variables of spring-tooth tools and speed rates of these harrows have been determined for most complicated conditions on heavy loamy soils. A new optimization criterion has been introduced in addition to soil pulverization degree. Harrow drawbar resistance has been determined as a function of drawbar category, operation recommendations have been proposed for KAMA-15 harrow and similar units equipped with spring-tooth tools.
\end{abstract}

Key words: minimum soil cultivation, heavy chisel spring harrow, spring-tooth tool, laboratory facility, experiment, optimization criterion, drawbar category.

\section{INTRODUCTION}

Soil cultivation is the most labor consuming procedure in agriculture. There are numerous variants of soil cultivation, the most common are conventional, minimum, and zero tillage. Each variant in this or that extent includes soil cultivation by harrowing. Harrowing is presented either as independent (separate) procedure or additional, auxiliary procedure.

Harrowing is performed using harrows. The aim of these machines is soil loosening with simultaneous homogeneous distribution of plant remains across field surface and covering of fertilizers as well as field levelling.

The important function of soil mulching in spring and autumn seasons as well as efficient distribution of stubbles in autumn after harvesting are performed the most efficiently by the heavy wide-level tooth harrows, their tools are comprised of pivotally mounted conical spring with one or two loose ends (hereinafter referred to as spring-tooth tool); it also should be mentioned that these tools are characterized by obvious advantages in comparison with their analogs rigidly fixed on frame.

The researchers [1-6] have no common opinion concerning the influence of variables of spring-tooth tool (position angle, cultivation depth, and travelling speed of machine-tractor aggregate (MTA)) on quality performances of harrow operation.

This work is aimed at provision of recommendation to use harrows with spring-tooth tools on the basis of the proposed optimization criterion.

This work is comprised of development of experimental procedures, production of laboratory facility, selection of optimization criterion and controllable factors, performance of experiments and data processing by regression analysis, establishment of rational process variables of harrow.

\section{METHODS}

The tests were performed on soil box by simulations. The experimental data were processed by mathematical statistics and regression analysis according to general and partial procedures.

The study subject was operation of spring-tooth tools of heavy wide-level harrow. This was aided by specially designed laboratory facility, Figure. 1. 

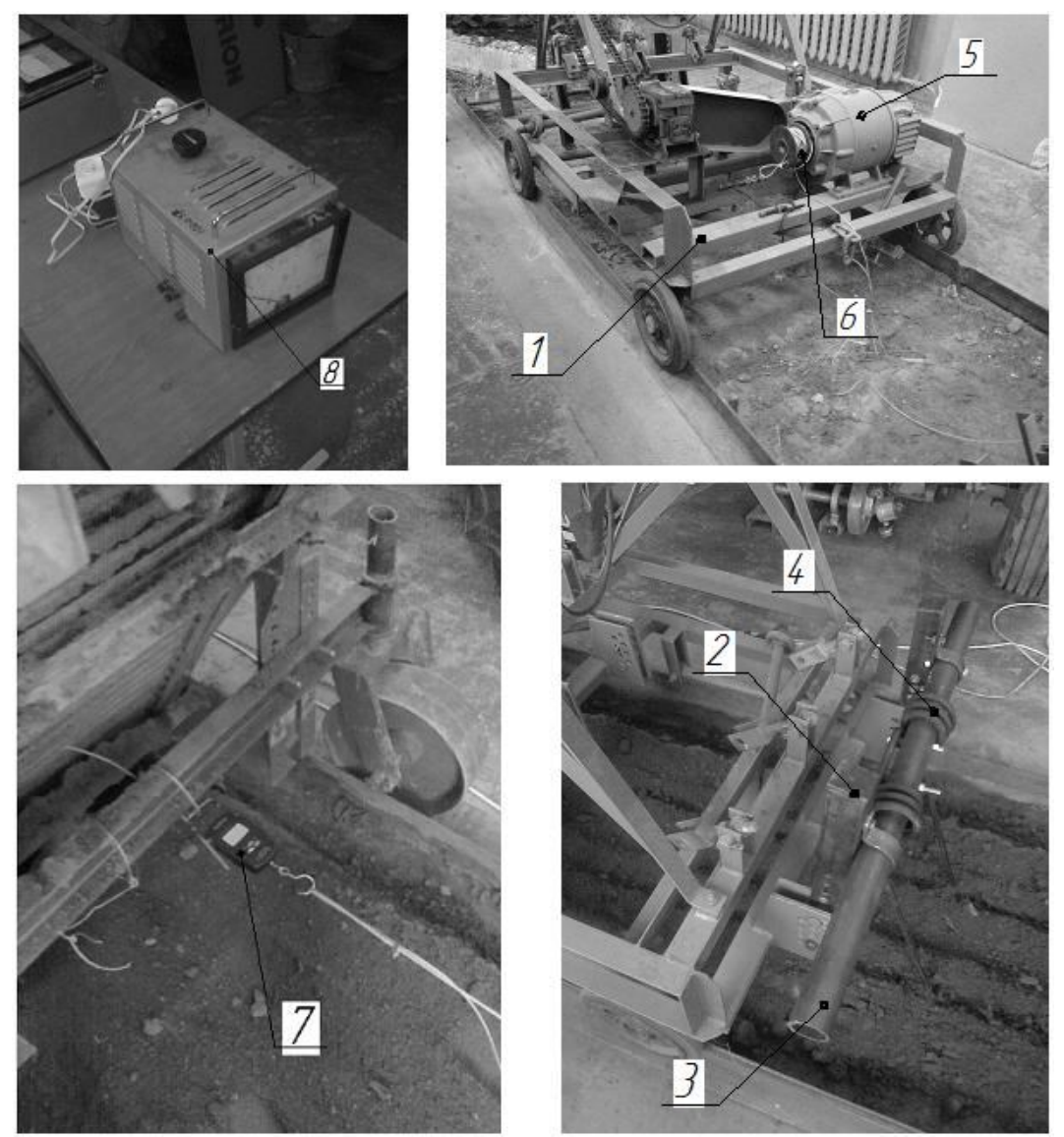

Figure 1: Laboratory facility

The facility is comprised of the frame 1; the adjusting angles 2; the mounting pipe 3; the spring-tooth tool 4; the DC motor 5; the rope 6 ; the recording dynamometer 7 ; the laboratory auto-transformer 8.

This facility simulated operation of spring-tooth tool of harrow. The performed tests would demonstrate not only soil crust pulverization but also loads of the tool during operation. Typical spring-tooth tools with the diameter of $16 \mathrm{~mm}$ of KAMA harrow were selected as references samples.

The facility is actuated by the DC motor 5 and the rope, one end of which is connected to the dynamometer 7 rigidly mounted on the frame, and the other end is wound on the motor pulley 6 . The DC motor allows to vary the platform travelling speed by variation of voltage on armature winding using the laboratory auto-transformer 8 .

When the facility is ready, the motor is activated, the rope is wound on the pulley, the platform 1 travels along the soil box, the tool 4 oscillates and loosens the soil. At the other end, the dynamometer records the force exerted to the spring-tooth tool.

Operation of the spring-tooth harrow tools is based on their interaction with soil aiming at pulverization of soil crust and clods. In order to understand completely this process, it is necessary to know mechanical properties of working body, that is, hardness and coefficient of volumetric soil compression which exert influence on tool drawbar resistance and soil capability to be destroyed under external impact. On the basis of these properties, it is possible to determine soil mechanical composition [6, 7].

This is aided by hardness tester (Fig. 2) [7].

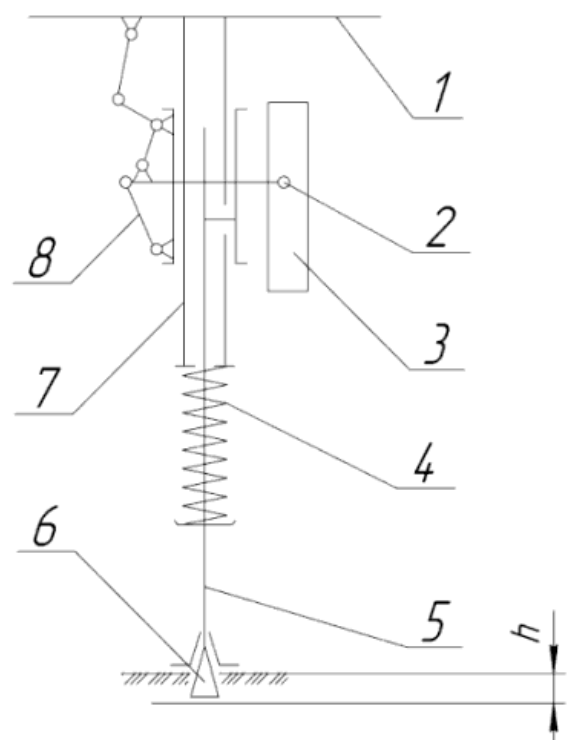

Figure 2: Revyakin's hardness tester: 1 - handle; 2 pencil; 3 - plotting paper; 4 - spring; 5 - rod; 6 - tip; 7 adaptor; 8 - transmission set. 
The hardness tester upon indenting the conical tip 6 into soil simultaneously records the forces in the plot 3 required for overcoming soil resistance and significantly depending on its density and moisture.

According to the relevant standard, the soil hardness should be detected using conical tip with the following parameters: for solid soil - base area of $100 \mathrm{~mm}^{2}$, apex angle of $22^{\circ} 30^{\prime}$, for loose soils $-200 \mathrm{~mm}^{2}$ and $30^{\circ}$, respectively. Herewith, the plot (Fig. 3) contains three peculiar segments corresponding to various stages of soil deformation.

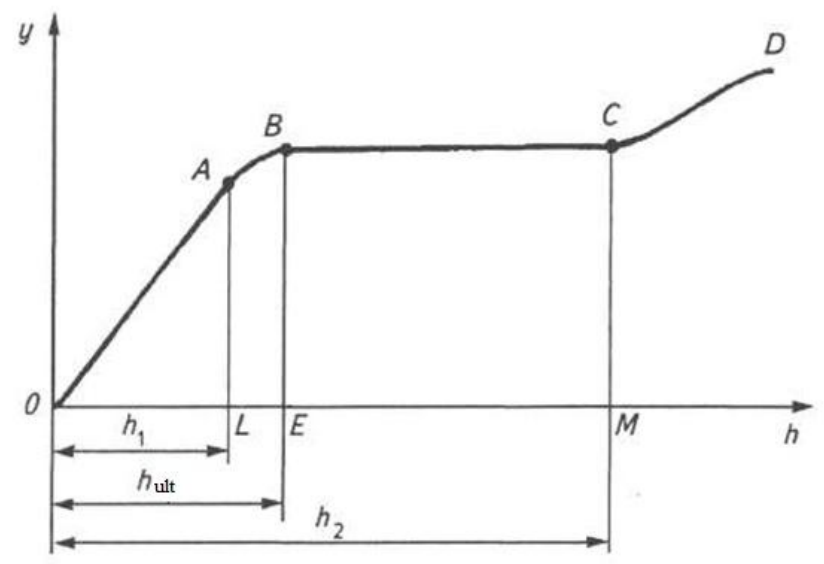

Figure 3: Deformation of hardness tester spring as a function of tip penetration depth

The initial stage of soil deformation is characterized by nearly linear increase in the force $F_{l}$ (segment $O A$ in the plot), low duration, and insignificant penetration depth of the tip $h_{l}$. The required force to overcome soil resistance is, $N$,

$$
F_{l}=k y_{l},
$$

where $k$ is the spring stiffness, $\mathrm{N} / \mathrm{mm} ; y_{l}$ is the spring deformation, $\mathrm{mm}$.

The second stage is characterized by lower increase in soil resistance against further tip penetration (segment $A B$ in the plot) and formation of conic body of strongly compacted soil in front of the tip which wedges out and densifies its lower levels. At the end of this stage (point $B$ ), the stress reaches the soil yield point.

The third phase of soil deformation (segment $B C$ in the plot) is characterized by continuous increase in the tip penetration depth at constant $F$. After the tip penetration to the topsoil depth $h_{2}$, the subsoil is located and the force $F$ rapidly increases (segment $C D$ in the plot).

With accounting for the plot, the soil hardness is, $\mathrm{Pa}$ :

$$
P=F_{l} / s=y_{l} k / s,
$$

where $s$ is the tip base area, $\mathrm{mm}^{2} ; y_{1}$ is the average ordinate of the plot in the segment $O A B, \mathrm{~mm}$.

Zheligovskii also proposes to detect the ultimate pressure $p_{u l t}$ on soil and the coefficient of volumetric soil compression. The ultimate pressure, $\mathrm{Pa}$, is predicted by the maximum ordinate (Fig. 3):

$$
P_{u l t}=y_{\max } k / s .
$$

The coefficient of volumetric compression, $\mathrm{N} / \mathrm{mm}^{3}$, which characterizes soil resistance against penetration during the first stage of deformation, is calculated as follows:

$$
q=F_{l}\left(s h_{1}\right)=y_{l} k /\left(s h_{l}\right),
$$

where $h_{l}$ is the soil deformation in the limits of direct proportionality of the plot (segment $O A$ ), mm.

The soil pulverization quality for compliance with the requirements of State standard GOST 26244-84 has been selected as the main optimization criterion during tests since this is the most important estimated variable upon soil cultivation.

The content of soil clods of various size in cultivated layer is determined experimentally by soil sampling in four various points at regular intervals along the distance of cultivated site (soil box in our case) (Fig. 4).

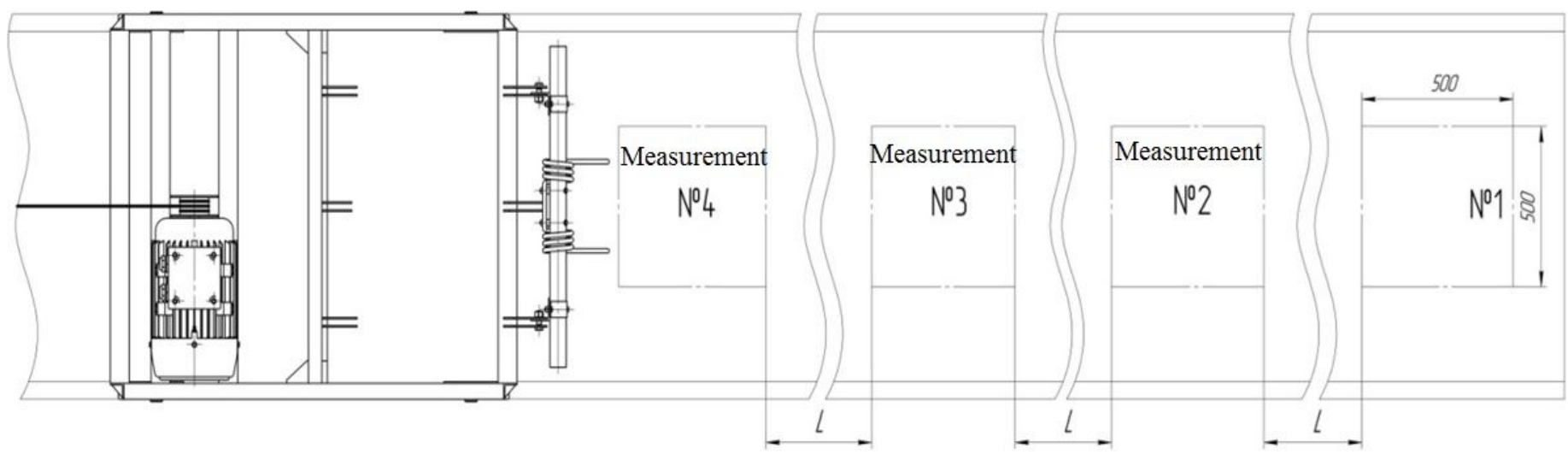

Figure 4: Sampling points in soil box

The soil cloddiness is determined using the $0.5 \times 0.5 \mathrm{~m}$ adaptor with a set of interchangeable screens with the holes of $2.5 \mathrm{~cm}$,
$5.0 \mathrm{~cm}$, and $10.0 \mathrm{~cm}$ (Fig. 5) as well as the scales with weighing error not higher than $50 \mathrm{~g}$. 

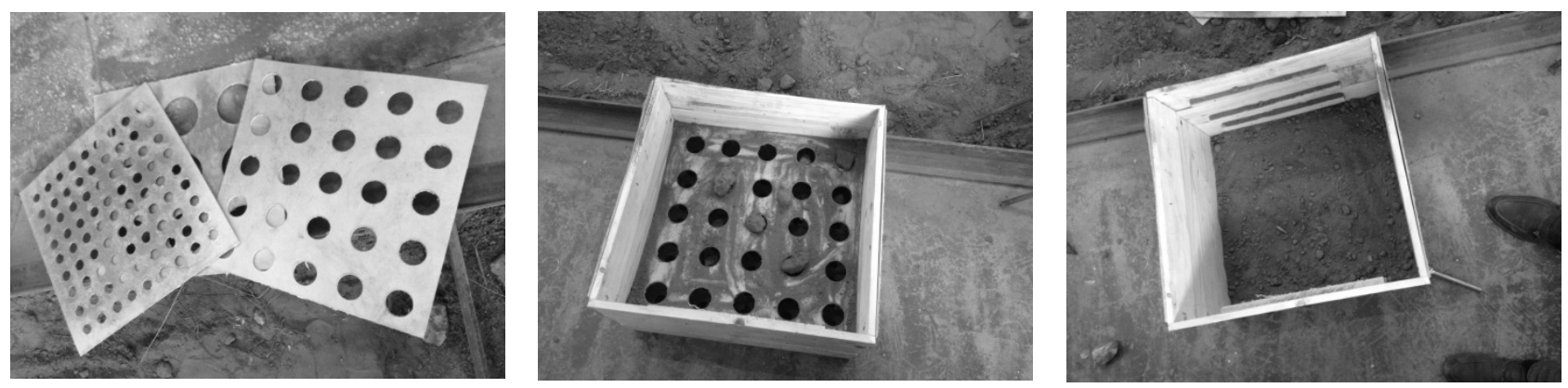

Figure 5: Adaptor with a set of interchangeable screens

The adaptor is placed onto soil, then the coarsest clods are selected to the soil cultivation depth, then the less coarse clods are selected and placed onto the screens of appropriate size. The screens in the set are located one under another in descending order of their hole diameters. A tray is placed under the screen set for all remaining soil with the clod diameter less than $2.5 \mathrm{~cm}$.
The soil bulk of each particle size is weighed separately with measurement error of not higher than $50 \mathrm{~g}$, then their weight percent is calculated with respect to overall weight and rounded to the nearest integer.

Table 1 summarizes the procedure of calculation of weight percentage of clods with various diameter after soil cultivation.

Table 1: Percentage content of soil clods of various diameter after cultivation

\begin{tabular}{|l|l|l|l|}
\hline \multirow{2}{*}{ Test No. } & \multicolumn{4}{|l|}{ Soil clods in terms of the highest diameter in cultivated soil layer } \\
\cline { 2 - 4 } & up to $\mathbf{2 . 5} \mathbf{~ c m}, \mathbf{~ k g}$ & $\mathbf{2 . 5} \ldots .5 .0 \mathbf{~ c m}, \mathbf{~ k g}$ & $\mathbf{5 . 0} \ldots . \mathbf{1 0 . 0} \mathbf{~ c m}, \mathbf{~ k g}$ \\
\hline Measurement № 1 & $\mathrm{A}_{1}$ & $\mathrm{~B}_{1}$ & $\mathrm{C}_{1}$ \\
\hline Measurement № 2 & $\mathrm{A}_{2}$ & $\mathrm{~B}_{2}$ & $\mathrm{C}_{2}$ \\
\hline Measurement № 3 & $\mathrm{A}_{3}$ & $\mathrm{C}_{3}$ \\
\hline Measurement № 4 & $\mathrm{B}_{3}$ & $\mathrm{C}_{4}$ \\
\hline Allowed by standard,\% & not more than 80 & $\mathrm{~B}_{4}$ & not more than 10 \\
\hline
\end{tabular}

The content of clods of various diameters is determined as average of five measurements [7].

In order to estimate efficiency of spring-tooth tools in various modes, the optimization criterion was proposed with the aim of quantitative comparison of the modes and to reduce them to comparable values. The optimization criterion $K_{\mathrm{opt}}$ shows specific power of resistance forces:

$$
K_{\mathrm{opt}}=\frac{N}{h}=\frac{F_{\mathrm{r}} \times V}{h}
$$

where $N$ is the power consumed for tool motion upon soil crust pulverization, $\mathrm{W} ; F_{\mathrm{r}}$ is the force of resistance against motion of spring-tooth tool (dynamometer readings), $\mathrm{N} ; V$ is the speed of the facility, $\mathrm{m} / \mathrm{s} ; h$ is the depth of soil cultivation, $\mathrm{m}$.

On the basis of published data on heavy wide-level harrows and methods of study of soil cultivation machinery [7, 8], the following adjustable factors effecting the optimization criterion were selected: $h$ - the depth of soil cultivation, $\mathrm{m} ; \alpha$ - the approach angle of spring-tooth tool, degrees; $V$ - the facility speed, $\mathrm{m} / \mathrm{s}$.

The facility provides adjustment of the mentioned factors.

The optimization criterion $K_{\mathrm{opt}}$ is a function of the aforementioned factors:

$$
K_{\text {opt }}=f(h, \alpha, V)
$$

According to the ranges achievable by existing heavy wide-level harrows with spring-tooth tools as well as according to agrotechnical requirements to surface tillage, the following variation limits of the factors were selected as summarized in Table 2.

\begin{tabular}{|c|c|c|c|c|}
\hline \multirow{3}{*}{ Indicator } & \multirow{3}{*}{$\begin{array}{l}\text { Coded } \\
\text { value }\end{array}$} & \multicolumn{3}{|l|}{ Factors } \\
\hline & & Cultivation depth $h, m$ & $\begin{array}{l}\text { Approach angle } \alpha \text {, } \\
\text { degree }\end{array}$ & Travelling speed $V, \mathbf{m} / \mathbf{s}$ \\
\hline & & $\mathbf{X} 1$ & $\mathbf{X} 2$ & X3 \\
\hline Upper level & +1 & 0.09 & 90 & 3.33 \\
\hline Main level & 0 & 0.07 & 75 & 2.50 \\
\hline
\end{tabular}

Table 2: Variation intervals and levels 


\begin{tabular}{|c|l|l|l|l|}
\hline Lower level & -1 & 0.05 & 60 & 1.67 \\
\hline Variation intervals & $\Delta \mathrm{Xi}$ & 0.02 & 15 & 0.83 \\
\hline
\end{tabular}

\section{RESULTS AND DISCUSSION}

The experiment with spring-tooth tools was performed according to central composite Box-Behnken design of the second order.

The tests were repeated three times. Soil in box was smoothed and compacted after each test so that to perform test under similar conditions. The dynamometer readings were recorded by camera, the averaged resistance forces were determined. All acquired experimental data were processed by methods of statistical analysis and experiment design [9-11]. After primary processing, the data were transferred to PC where they could be analyzed using StatGraphicsPlus v5.0. The software calculated the regression coefficients and plotted response surfaces.

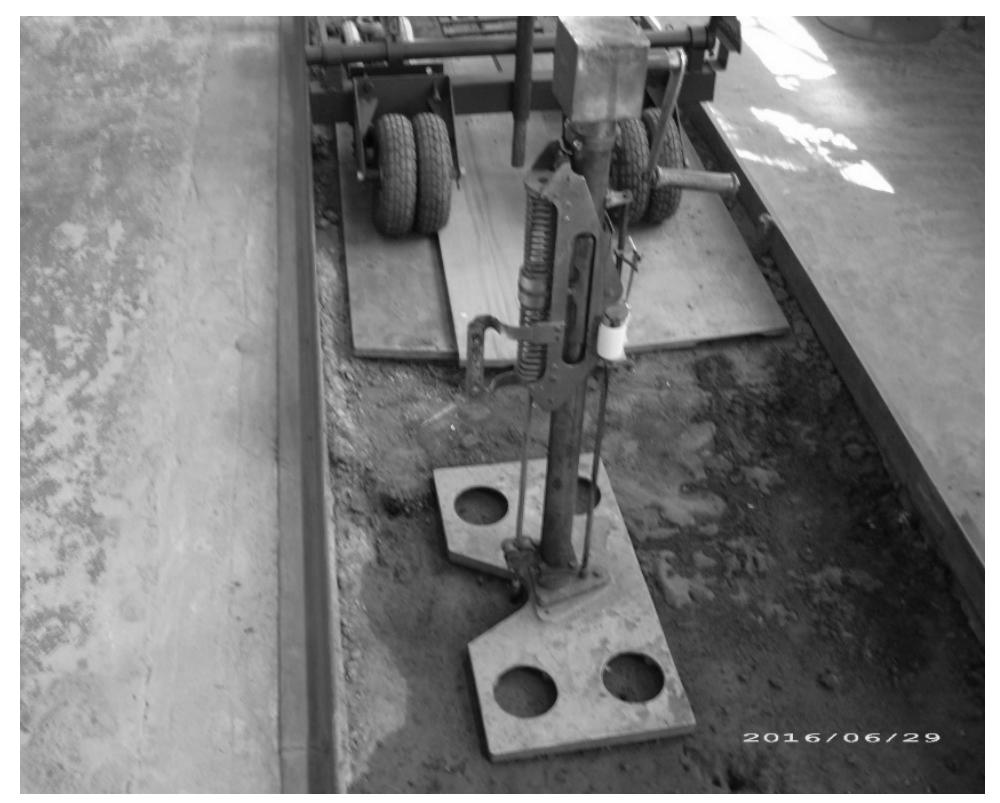

Figure 6: Determination of soil hardness in soil box using Revyakin's hardness tester

The experiments were performed in soil box at the moisture content of $25 \ldots 30 \%$. Soil hardness patterns were plotted in five points along the soil box (Fig. 6).

Figure 7 illustrates the acquired load diagrams. The ordinate $y_{1}$ shows the deformation of hardness tester spring, that is, it is proportional to soil resistance. The constant of the spring installed in hardness tester is $k=8.54 \mathrm{~N} / \mathrm{mm}$. The abscissa $h$ shows the depth where hardness is measured, the scale factor to determine the depth is $\mu_{h}=0.00312 \mathrm{~m} / \mathrm{mm}$.

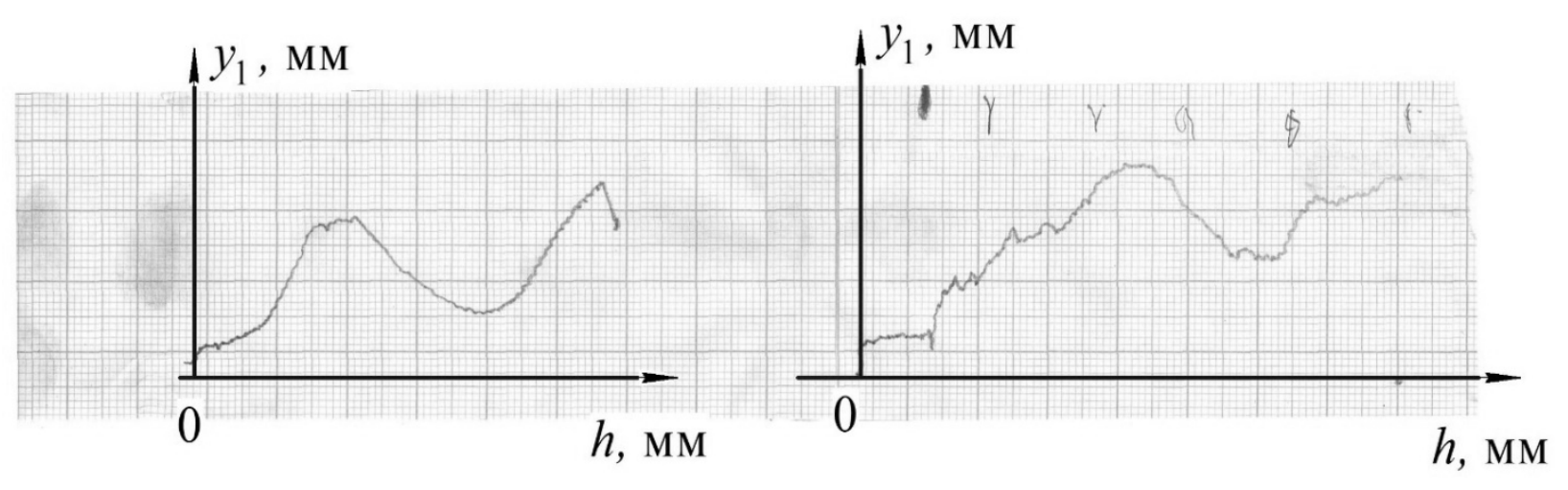

Figure 7: Soil hardness patterns

Figure 8 illustrates averaged force of resistance and soil hardness as a function of depth $h$ of measurements. It can be seen that the resistance patterns in all points across the depth are similar, though, the numerical values vary. Up to the depth of $0.08 \ldots 0.12 \mathrm{~m}$, the resistance and the soil hardness increase, then these properties decrease, and after $0.16 \mathrm{~m}$ they 
again increase.

\section{a) Average soil resistance, $\mathbf{N}$}

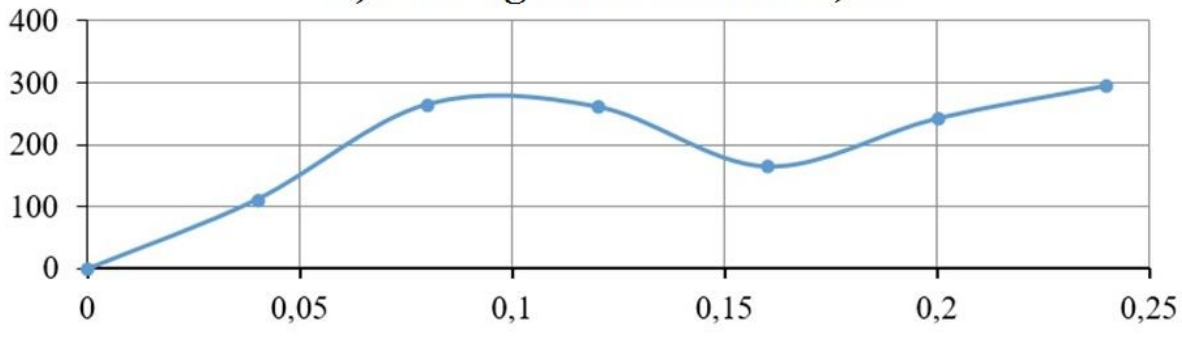

Cultivation depth $h, \mathrm{~m}$

b) Average soil hardness $p$, MPa

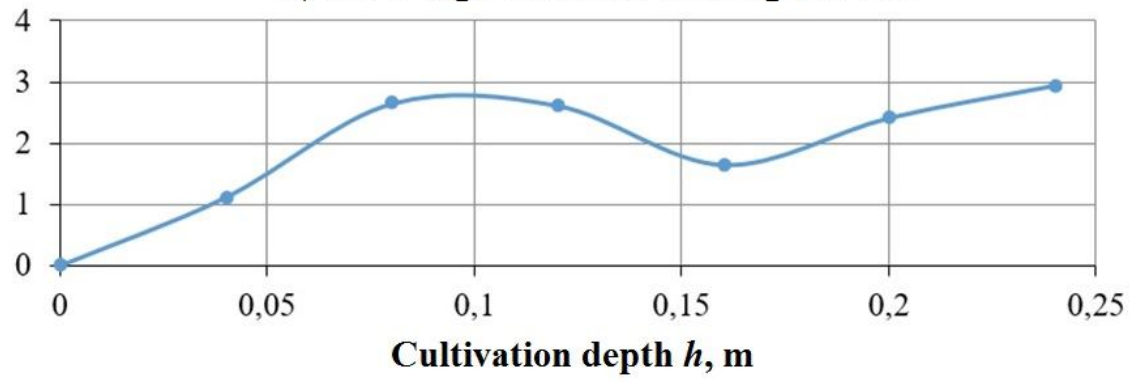

Figure 8: Average resistance (a) and soil hardness $p$ (b) as a function of depth $h$.

In the area of concern $0.05 \ldots 0.12 \mathrm{~m}$, the average soil hardness increases with the depth. The average calculated hardness is $\left[p_{1}\right]=2.13 \pm 0.37 M P a$, the ultimate hardness is $p_{1}=3.84 \mathrm{MPa}$, which according to the classification in [10] corresponds to loose soil in air dry state. This soil state agrees well with previously cultivated plough layers. Particle size distribution of soil in the box corresponds to medium loams as most soils in Udmurtia.

The coefficient of volumetric compression according to Eq. (4) for the segment of linearly dependence (Fig. 8) observed at the depth $h_{1}=0.08 \mathrm{~m}=80 \mathrm{~mm}$ is as follows:

$$
q=\frac{\left\langle p_{1}\right\rangle}{h_{1}}=\frac{2.13}{80}=0.0266 \frac{\mathrm{N}}{m m^{2}}
$$

This also confirms loose and porous composition of the soil. According to the experiment design, Table 3.2, as well as the level of factor variation, Table 3.1, the experiments were performed for three spring-tooth tools: typical spring-tooth tool made of rod with the diameter $d=14 \mathrm{~mm}$, typical spring-tooth tool made of rod with the diameter $d=16 \mathrm{~mm}$, new spring-tooth tool made of rod with the diameter $d=16$ $\mathrm{mm}$.

Idle run of the laboratory facility without spring tools made it possible to determine own resistance against motion along soil box. After processing of the dynamometer data, the resistance of platform without spring tools was determined: $F_{r}{ }^{0}=199.8 \mathrm{~N}$.

On the basis of the experimental results the influence of the factors on the optimization criterion was determined, Tables 3 and 4 .

Table 3: Average soil cloddiness after soil cultivation by various spring-tooth tools

\begin{tabular}{|c|l|l|l|}
\hline \multirow{2}{*}{} & \multicolumn{2}{|l|}{ Clods in soil,\% } \\
\cline { 2 - 4 } & up to $2.5 \mathrm{~cm}$ & from 2.5 to $5.0 \mathrm{~cm}$ & from 5.0 to $10.0 \mathrm{~cm}$ \\
\hline $\begin{array}{c}\text { Typical spring-tooth tool with the rod } \\
\text { diameter } d=16 \mathrm{~mm}\end{array}$ & 75.6 & 14.3 & 10.1 \\
\hline Allowed by standard,\% & not more than 80.0 & $\ldots$ & not more than 10.0 \\
\hline
\end{tabular}


Alexey Genrichovitsch Ivanov et al., International Journal of Emerging Trends in Engineering Research, 8(3), March 2020, 695- 704

Table 4: Experimental results for typical spring-tooth tool made of rod with the diameter of $16 \mathrm{~mm}$

\begin{tabular}{|c|c|c|c|c|c|c|c|}
\hline \multirow[b]{2}{*}{ № } & \multirow[b]{2}{*}{$X_{1}-$ depth } & \multirow[b]{2}{*}{$X_{2}$ - angle } & \multirow[b]{2}{*}{$X_{3}$ - speed } & \multirow[b]{2}{*}{ Processed data $F_{\mathrm{r}}, \mathrm{N}$} & \multirow{2}{*}{$\begin{array}{l}\text { Optimization criterion, } \\
K_{\text {opt }}\end{array}$} & \multicolumn{2}{|c|}{ Clods in soil, \% } \\
\hline & & & & & & up to $2.5 \mathrm{~cm}$ & $5-10 \mathrm{~cm}$ \\
\hline 1 & 1 & 0 & 1 & 564.79 & $20,893.54$ & 78 & 12 \\
\hline 2 & -1 & 0 & 1 & 363.10 & $24,183.68$ & 78 & 10 \\
\hline 3 & 0 & 1 & 0 & 416.30 & $14,885.79$ & 68 & 9 \\
\hline 4 & -1 & -1 & 1 & 311.10 & $20,701.65$ & 79 & 13 \\
\hline 5 & 1 & 1 & 0 & 319.21 & $8,866.38$ & 81 & 9 \\
\hline 6 & 0 & 0 & 0 & 303.88 & $10,847.25$ & 85 & 5 \\
\hline 7 & -1 & 1 & 1 & 141.87 & $9,451.23$ & 81 & 15 \\
\hline 8 & 0 & 1 & 1 & 356.49 & $16,951.18$ & 67 & 13 \\
\hline 9 & 0 & 0 & 0 & 303.28 & $10,839.91$ & 73 & 5 \\
\hline 10 & 1 & 0 & -1 & 246.17 & $4,559.04$ & 82 & 5 \\
\hline 11 & 0 & -1 & 1 & 384.74 & $18,284.54$ & 83 & 7 \\
\hline 12 & 0 & -1 & -1 & 285.55 & $6,822.65$ & 65 & 9 \\
\hline 13 & 0 & 0 & 0 & 303.78 & $10,849.24$ & 60 & 13 \\
\hline 14 & 1 & -1 & -1 & 313.20 & $5,811.51$ & 79 & 11 \\
\hline 15 & -1 & 0 & 0 & 153.00 & $7,650.16$ & 75 & 15 \\
\hline \multicolumn{6}{|c|}{ Average cloddiness, $\%$} & 75.6 & 10.1 \\
\hline
\end{tabular}

Mathematical model for new spring-tooth tool with the diameter of $16 \mathrm{~mm}$ is as follows:

$$
\begin{gathered}
K_{\text {opt }}=15,573+3,337 X_{1}+3,351 X_{2}+5,229 X_{3}-3,717 X_{1}^{2}- \\
-337 X_{1} X_{2}+671 X_{1} X_{3}+134 X_{2}^{2}+216 X_{2} X_{3}+851 X_{3}^{2} .
\end{gathered}
$$

Equation (7) shows that in the preset intervals of factor variation, the optimization criterion is exerted to the equal influence of all three criteria: the depth of cultivation by spring tool $X_{1}$, the approach angle of spring tool $X_{2}$, the travelling speed $X_{3}$. The minus sign before the coefficient indicates at decrease in the optimization parameter upon increase in the considered parameter, and the plus sign indicates at increase in the parameter.

Figures 9, 10 illustrate the criterion $K_{\text {opt }}$ as a function of the mentioned factors (single effects) and response surfaces obtained by means of StatGraphicsPlus v5.0.

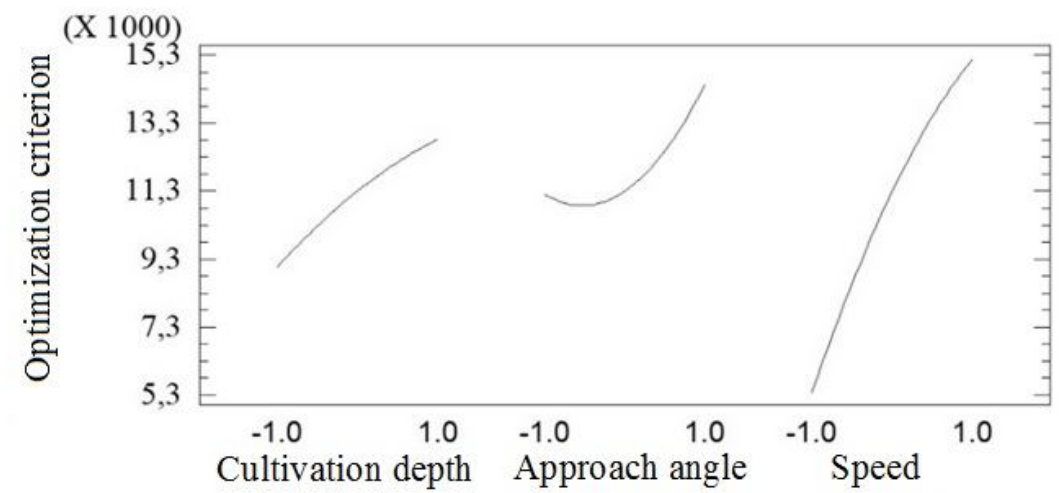

Figure 9: Optimization criterion as a function of factors (typical spring-tooth tool with the diameter of $16 \mathrm{~mm}$ ) 

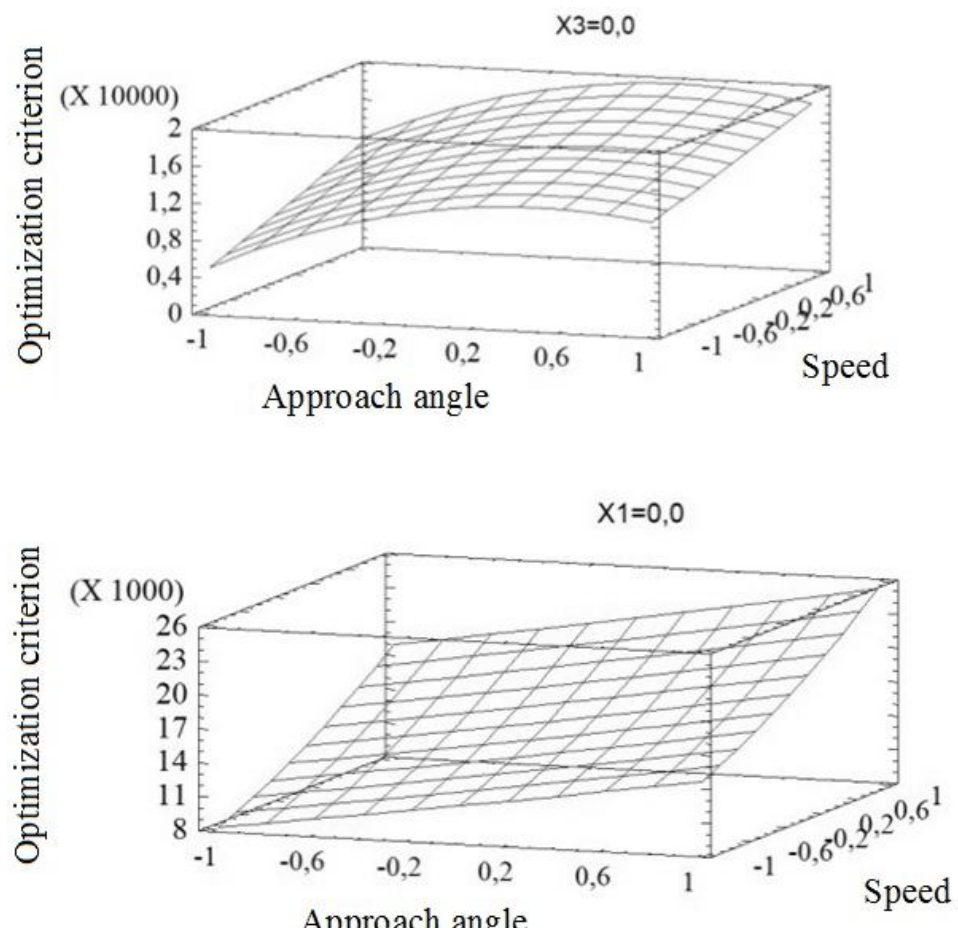

Approach angle

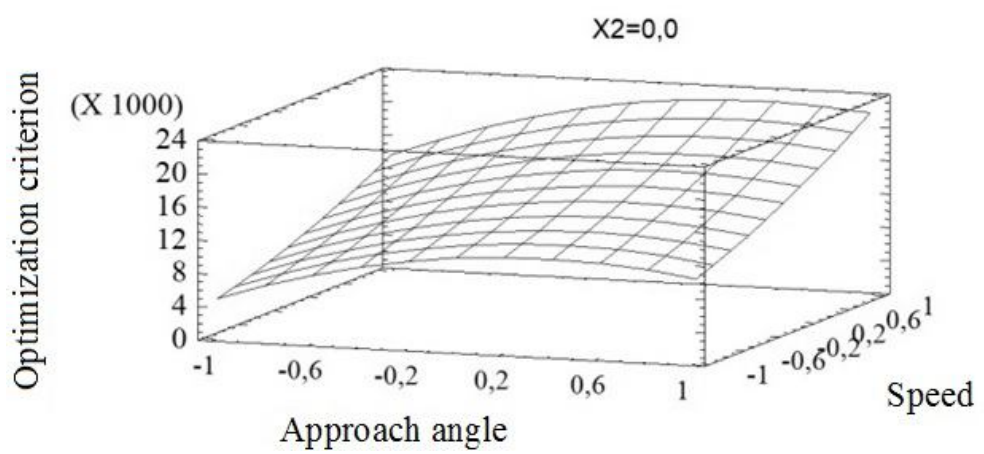

Figure 10: Response surfaces (typical tool, $\mathrm{d}=16 \mathrm{~mm}$ ).

Using StatGraphicsPlus v5.0, the maximum values of Eq. (7) were determined in the considered area of variation of adjustable factors:

$$
X_{1}=1.0, X_{2}=0.99, X_{3}=0.92 .
$$

Therefore, after conversion of coded factors into actual values, the rational values of cultivation depth, approach angle, and tool travelling speed were determined. Such adjustments guarantee the optimum use of harrow with the highest specific work consumed for soil cultivation:

Typical spring-tooth tool made of $16 \mathrm{~mm}$ rod

$\checkmark$ soil cultivation depth $h=0.09 \mathrm{~m}$;

$\checkmark$ tool approach angle $\alpha=89^{\circ} 51^{\prime}$;

$\checkmark$ harrow travelling speed $V=3.26 \mathrm{~m} / \mathrm{s}(11.7 \mathrm{~km} / \mathrm{h})$.

The rational depth of soil cultivation by tool made of $16 \mathrm{~mm}$ rod is higher than that of tool made of $14 \mathrm{~mm}$ rod. Herewith, the drawbar resistance is also higher both due to higher cultivation depth and due to higher surface area of midsection. This can be attributed to the fact that, other conditions being equal, a thicker rod is characterized by higher rigidity. In order to bend it similarly to thinner rod, higher effort is required. It is achieved by higher resistance of soil. Thus, the spring-tooth tools made of $16 \mathrm{~mm}$ rod can be applied for higher cultivation depth.

The harrow travelling speed is the speed of tractor and depends on its drawbar category. Harrow can operate at the speed higher than $12 \mathrm{~km} / \mathrm{h}$. For tools of spring-tooth type, the speeds up to $15 \mathrm{~km} / \mathrm{h}$ are recommended to generate intensive vibration of tools and good pulverization of soil clods. However, it should be considered that many tractors in agriculture are based on $4 \mathrm{~K} 4$ wheel arrangement so that to increase drawbar capabilities. And all-wheel drive of modern tractors is deactivated automatically at the speeds higher than $12 \mathrm{~km} / \mathrm{h}$. Thus, the working speed of $15 \mathrm{~km} / \mathrm{h}$ can be applied only to tractors with constant all-wheel drive.

At the highest experimental depth of soil cultivation $h=0.09$ $\mathrm{m}\left(X_{1}=1.0\right)$, the tool approach angle $\alpha=90^{\circ}\left(X_{2}=1.0\right)$ and with consideration for Eq. (5), we obtain the equation for drawbar resistance $F_{\mathrm{r}}$ based on Eq. (7):

$$
K_{o v}=15,122+7,197 X_{n}-1,012 X_{2}^{2} \text {, }
$$


Alexey Genrichovitsch Ivanov et al., International Journal of Emerging Trends in Engineering Research, 8(3), March 2020, 695- 704

$$
F_{r}=\left[15,122+7,197 \frac{V-\langle V\rangle}{\langle V\rangle}-1,012\left(\frac{V-(V)}{\langle V\rangle}\right)^{2}\right] \frac{h}{V} .
$$

where $K_{\text {opt }}$ is the optimization criterion, $\mathrm{N} / \mathrm{m} ; X_{3}$ is the coded value of harrow speed; $V$ is the travelling speed of MTA, $\mathrm{m} / \mathrm{s} ;[V]$ is the average speed of the facility applied in the experiments, $[V]=2.5 \mathrm{~m} / \mathrm{s}$.

Using Eq. (8), it is possible to determine drawbar resistance at any speed of the facility. The drawbar efforts required for operation of harrow with the number of spring-tooth tools $\mathrm{Z}=$ 120 at various speeds are summarized in Table 5.
Equation (8) describes quadratic dependences (parabolas) for determination of drawbar resistance at the cultivation depth of 0.09 and the approach angle of $90^{\circ}$. In the considered range of factor variation, the ascending branches of parabolas are observed characterized by significant curvature radius. They can be approximated by linear dependence. While predicting drawbar resistance for other soil types, the calculated values can be varied proportionally to hardness of preset soil type in comparison with that selected for laboratory tests.

Table 5: Drawbar category as a function of MTA travelling speed

\begin{tabular}{|c|c|c|c|}
\hline MTA speed $V, \mathbf{k m} / \mathbf{h}$ & $\begin{array}{l}\text { Drawbar force with typical tools } \mathrm{d}= \\
16 \mathrm{~mm}, \mathrm{~N}\end{array}$ & $\begin{array}{l}\text { Drawbar category of } \\
\text { aggregated tractor }\end{array}$ & Tractor model \\
\hline 6 & $23,495.3$ & \multirow{4}{*}{ At least 2} & \multirow{4}{*}{$\begin{array}{l}\quad \checkmark \text { Belarus } 1220 \\
\text { T-70 } \\
\text { John Deere } 6020\end{array}$} \\
\hline 7 & $24,601.1$ & & \\
\hline 8 & $25,699.9$ & & \\
\hline 9 & $28,200.4$ & & \\
\hline 10 & $32,014.8$ & \multirow{3}{*}{ At least 3} & $\checkmark \mathrm{T} 150 \mathrm{~K}$ \\
\hline 11 & $34,297.7$ & & $\checkmark$ DT-75 \\
\hline 12 & $36,660.1$ & & $\checkmark$ Terrion ATM 3180 \\
\hline
\end{tabular}

It can be seen in Table 5 that with the increase in speed, the harrow drawbar force increases linearly. For operation of harrow with the width of $15 \mathrm{~m}$ (120 spring tools), the tractors of drawbar category of at least $3.0 \mathrm{tf}$ should be used.

\section{CONCLUSION}

It has been established that upon cultivation of heavy loamy soils with the moisture of $25 \ldots 30 \%$ at average coefficient of soil hardness $\left[p_{1}\right]=2.13 \pm 0.37 \mathrm{MPa}$ at the depths of $0.05 \ldots 0.12 \mathrm{~m}$ using spring-tooth tools made of rod with the diameter of $16 \mathrm{~mm}$, the requirements of State standard GOST 26244-84 are met: in the cultivated soil layer, the content of clods with maximum diameter up to $2.5 \mathrm{~cm}$ reaches in average $75.6 \%$ of total bulk of cultivated soil and the content of clods with the diameter from 5 to $10 \mathrm{~cm}$ does not exceed $10 \%$. Therefore, in order to select rational variables of harrow with spring tools, it would be reasonable to introduce optimization criterion showing specific power of force per unit cultivation depth. Laboratory studies of the tools have resulted in regression equation with respect to optimization coefficient on the basis of which the factors were determined providing rational operation mode of harrow equipped with spring-tooth tools:

Typical spring-tooth tool made of $16 \mathrm{~mm}$ rod

$\checkmark$ soil cultivation depth $h=0.09 \mathrm{~m}$;

$\checkmark$ tool approach angle $\alpha=89^{\circ} 51^{\prime}$;

$\checkmark$ harrow travelling speed $V=3.26 \mathrm{~m} / \mathrm{s}(11.7 \mathrm{~km} / \mathrm{h})$.

On the basis of the regression equation, the drawbar resistance of tools has been empirically determined as a function of MTA travelling speed at the cultivation depth $h=$ $0.09 \mathrm{~m}$ and the tool approach angle $\alpha=90^{\circ}$ :

$$
F_{r}=\left[15,122+7,197 \frac{V-(V)}{(V)}-1,012\left(\frac{V-(V)}{\langle V\rangle}\right)^{2}\right] \frac{h}{V^{\prime}}
$$

The resistance of spring-tooth tools increases with speed. The required tractor drawbar upon aggregating with harrows has been determined equaling to $17.6 \ldots 36.7 \mathrm{kN}$.

\section{REFERENCES}

1. Discount Agromarket: Soil cultivation systems for various cultures. Available

at: http://www.discount-agromarket.ru/ru/sistemy-obrabotki-poc hvy-pod-razdichny-e-kul-tury/

2. Lira Xl-Heavy Tooth Harrow. Available at: https://lozovamachinery.com/en/products/519/5436/

3. Magnum Drawbar Harrow. Available at: https://www.gatesmfg.net/wp-content/uploads/2018/11/Drawb ar-Harrow-Parts-Book.pdf

4. V. Bulgakov, S. Ivanov, V. Bandura, Y. Ihnatiev. Experimental investigation of harrow with spring teeth for cultivation of sugar beets. Engineering for rural development, Jelgava, 23-25 May, 2018. DOI: 10.22616/ERDev2018.17.N259

5. S. Crittenden, N. Poot, M. Heinen, D. Van Balen, M. Pulleman. Soil physical quality in contrasting tillage systems in organic and conventional farming. Soil and Tillage Research, 154, pp.136-144, 2015.

6. S.R. Bello. Agricultural Machinery \& Mechanization. Charl US: Createspace, p. 448, 2012.

7. GOST RF 26244-84 Presowing soil treatment. Quality requirements and methods for determination. Moscow: Standartinform, 1984.

8. D.A. Abduvahobov, J. Muhamedov, A.H. Umurzakov. Layout diagram of the hinged oscillatory spike-tooth harrow and determination of its row-spacing width. European science review, 5-6, pp. 175-176, 2016.

9. A.P. Bodalev, A.G. Ivanov, A.V. Kostin. Obosnovanie parametrov i rezhimov raboty tyazheloi sternevoi pruzhinnoi 
Alexey Genrichovitsch Ivanov et al., International Journal of Emerging Trends in Engineering Research, 8(3), March 2020, 695- 704

borony [Substantiation of operation variables and modes of heavy chisel spring harrow]. AgroEkoInfo, 1(31), pp. 34, 2018.

10. A.P. Bodalev, A.G. Ivanov, A.V. Kostin. Opredelenie optimal'nykh parametrov raboty tyazheloi pruzhinnoi zubovoi borony na pochvakh Udmurtskoi Respubliki [Determination of optimum process variables of heavy spring-tooth harrow on soils of Udmurtia]. In: Scientific support and human resourcing of agribusiness industry for food import substitution. Proceedings: All-Russian scientific and conference. Ministry of Agriculture of the Russian Federation, Izhevsk State Agricultural Academy, pp. 5-13, 2016.

11. R. Berntsen, B. Berre. Soil fragmentation and the efficiency of tillage implements. Soil \& Tillage Research, 64(1-2), pp. 137-147, 2002. 